\title{
Seizures in posterior reversible encephalopathy syndrome: blood pressure management in normotensive patients
}

\author{
Lu Lu, Weixi Xiong, Yingying Zhang, Yingfeng Xiao and Dong Zhou*
}

\begin{abstract}
Posterior reversible encephalopathy syndrome (PRES) is a rare clinical disease that refers to the subcortical vasogenic edema involving bilateral parieto-occipital regions, with a usually reversible syndrome when causes are eliminated or controlled. Hypertension or blood pressure fluctuations are most common causes of PRES, but other contributors like chemotherapy and autoimmune disorders have also been reported. PRES has rapid onset of symptoms. Therefore, it is of major importance to determine whether blood pressure management plays an important role in prognosis. We presented two PRES patients who developed non-convulsive seizure but had normal baseline blood pressure at the time of presence of cause. The diagnosis of PRES was made by neurologists. The patients had no history of seizure or hypertension, but during the disease course they presented with temporal elevation of blood pressure with different durations. The second patients without instant blood pressure control developed residual symptoms of seizure at 90- and 120-day follow-up. Although the exact pathophysiology of PRES remains to be fully understood, primary and secondary prolonged blood pressure fluctuations may be associated with the prognosis of this syndrome. Early blood pressure management would be critical to favorable outcome.
\end{abstract}

\section{Background}

Posterior reversible encephalopathy syndrome (PRES), also known as the reversible posterior leukoencephalopathy syndrome (RPLS), is a condition associated with radiographic features of subcortical vasogenic brain edema involving bilateral parieto-occipital regions. It occurs in circumstances of renal failure, blood pressure fluctuations, use of cytotoxic drugs, autoimmune disorders, or eclampsia. Hypertension is commonly seen during the disease course [1]. It has been reported that $15-20 \%$ of PRES patients are normotensive or even hypotensive [2]. Profound fluctuations of blood pressure may also contribute to the syndrome [3]. Clinically, PRES is characterized by encephalopathy (50-80\%), seizure (60-75\%),

*Correspondence: zhoudong66@yahoo.de

Department of Neurology, West China Hospital, Sichuan University,

Chengdu 610041, Sichuan, China headache (50\%), visual disturbances (33\%), focal neurological deficit (10-15\%), and status epilepticus (5-15\%) [4, 5]. The presence of these neurological symptoms, either acute or subacute, under the mentioned circumstances, may suggest the diagnosis of PRES, although the symptoms and signs of PRES are not specific. Brain imaging is the primary tool for verification.

There is no specific treatment for PRES, but the disorder is usually reversible when causes are eliminated. However, the residual neurologic deficits are reported to occur in up to $44 \%$ of PRES patients [6]. General consensus from clinical experience suggests that the treatment to hypertension is important in the prognosis of PRES, but no studies have been done to analyze the effect. Here we present two cases of PRES with different etiology. They both developed seizures during the course. The initial blood pressure was not extremely altered in either patient, but the long-lasting consequences suggested original author(s) and the source, provide a link to the Creative Commons licence, and indicate if changes were made. The images or other third party material in this article are included in the article's Creative Commons licence, unless indicated otherwise in a credit line to the material. If material is not included in the article's Creative Commons licence and your intended use is not permitted by statutory regulation or exceeds the permitted use, you will need to obtain permission directly from the copyright holder. To view a copy of this licence, visit http://creativecommons.org/licenses/by/4.0/. 
the importance of blood pressure management in the prognosis.

\section{Case 1}

The patient was a 52-year-old woman who was admitted to the respiratory ward for acute lung infection with pulmonary arterial hypertension. She had suffered symptoms of cheat tightness and shortness of breath after activities for two years and then was treated with tadalafil $(20 \mathrm{mg}$ bid po) for 8 months. The pulmonary artery pressure (PAP) remained to be $73 \mathrm{mmHg}$ after treatment. She had tuberculosis 30 years ago, for which she received isoniazid, rifampicin, ethambutol, pyrazinamide (HREZ) plan irregularly for half a year. The chest X-ray scan showed damage of the left lung for 19 years. No history of hypertension was reported.

At admission, the diagnosis was considered as chronic pulmonary heart disease, cardiac insufficiency, lung infection, old pulmonary tuberculosis and prerenal renal insufficiency, so anti-infection treatment and diuretics were given. She developed type 2 respiratory failure on the next day ( $\mathrm{PaO} 2129.7 \mathrm{mmHg}, \mathrm{PaCO} 272.8 \mathrm{mmHg}$ ), and was occupied with non-invasive ventilator treatment. Depression was continuingly observed from admission. Her blood pressure was $95 / 52 \mathrm{mmHg}$ at admission, raised up to $118 / 78 \mathrm{mmHg}$ on day 5 , and remained stable on the following days. The ventilation support was weaned on day 9 after admission, when she had normal temperature and respiratory and renal functions, and stable vital signs. Three hours later, she experienced sudden dizziness and developed gazing of the eyes, loss of consciousness, and convulsion of the left upper limb for $2 \mathrm{~min}$. The blood pressure was $97 / 78 \mathrm{mmHg}$, the respiratory rate was 16 times/min, and the left pupil light reflection was slow. She was again occupied with ventilator support, and became conscious $10 \mathrm{~min}$ later. Four hours later, she had a sudden fist of both hands, loss of consciousness and developed a generalized tonic-clonic seizure which lasted for $5 \mathrm{~min}$. These symptoms were eliminated by injection of diazepam $(5 \mathrm{mg})$ and phenobarbital $(100 \mathrm{mg}$, intramuscular injection). The blood pressure increased to $138 / 94 \mathrm{mmHg}$. The contrast-enhanced MRI scan showed subcortical abnormal signals predominantly in bilateral posterior regions (Fig. 1). Cerebrospinal fluid was tested for autoimmune antibody and infection, and negative results were obtained. The blood pressure did not profoundly fluctuate after the second seizure, which remained around $110 / 75 \mathrm{mmHg}$ during the whole course (Fig. 2). She was prescribed with phenobarbital $(100 \mathrm{mg}$, intramuscular injection) and levetiracetam $(1000 \mathrm{mg}$, oral). The patient did not have any seizure episode in the next 5 days, and the phenobarbital treatment was gradually stopped. Other investigations provided no specific evidence, so she was diagnosed as PRES. The respiratory failure was corrected on day 14, and the ventilator was withdrawn. She was discharged on day 15 . The levetiracetam treatment was stopped at 1-month follow-up. No seizure was reported during the 3-month follow-up.

\section{Case 2}

The patient was a 43-year-old woman admitted to the department of hematology in our center for sibling donor hematopoietic stem cell transplantation. She was diagnosed with paroxysmal nocturnal hemoglobinuria 8 years ago. The pre-chemotherapy FB treatment (fludarabine $50 \mathrm{mg}$ D-6 - 2, busulphan $165 \mathrm{mg}$ D-6 -3) was started on day 2 after admission. The patient was infused with $190 \mathrm{ml}$ of type B, Rh-positive sister-derived HLA-matched peripheral hematopoietic stem cells on day 9 the following test suggested successful stem cell transplantation. She was then treated with cyclophosphamide and ciclosporin for transplantation rejection prevention. She had no history of hypertension. Her blood pressure before chemotherapy was stable, ranging $115-125 / 65-75 \mathrm{mmHg}$. Three days after the initial cyclophosphamide, the blood pressure started to rise and reached $141 / 77 \mathrm{mmHg}$ on day 18 . She reported headache and was agitated from day 30 ,

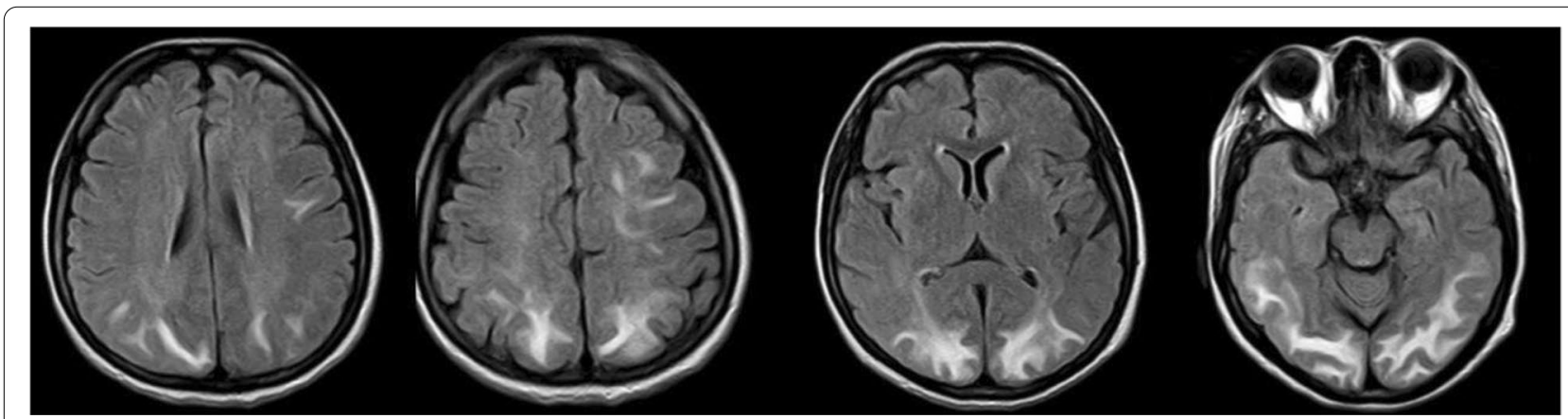

Fig. 1 MRI of case 1 on day 12. The parietal, temporal, and occipital lobes exhibited index finger-like abnormality, long T1, long T2, high FLAIR signal, and fuzzy boundaries 


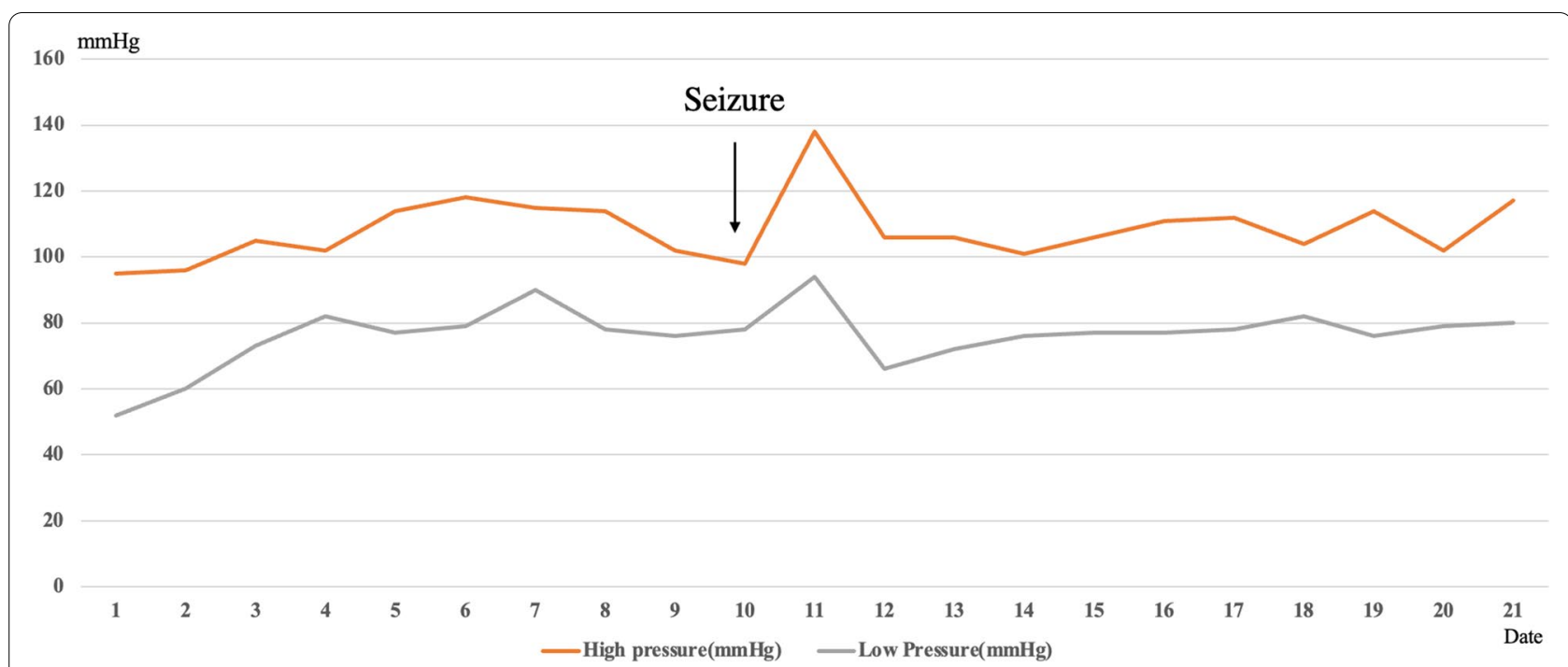

Fig. 2 Blood pressure fluctuations of case 1. The horizontal presents length of in-hospital stay. Blood pressure elevation started after seizure attack at Day 9. It was controlled and remain stable Since Day 12

when the blood pressure was $129 / 81 \mathrm{mmHg}$. Within a few hours, she was irritated, demonstrated delirium and impairment in orientation. Red blood cell debris was found in her peripheral blood smears, then she was diagnosed as transplantation-associated thrombotic microangiopathy (TA-TMA) or other secondary intracranial lesion. Abnormal MRI signals were found mainly in the bilateral occipital lobes (Fig. 3). Ciclosporin was instantly discontinued, replaced with the Mycophenolate Mofetil and Cortisol therapy. Her body temperature increased on day 31 , and vancomycin was applied for anti-infection. The patient remained agitated and was treated with $10 \mathrm{mg}$ haloperidol. Considered as TMA, the patient was treated with haloperidol, rituximab and plasma. The blood pressure increased to $176 / 91$ on day 33 . The temperature was still high on day 37 , reaching $38.4^{\circ} \mathrm{C}$. The patient had the first seizure, starting with convulsion in the left upper limb for 2 min, while the consciousness did not go back to baseline level, both cases developed convulsion in the left upper limb and eye gazing toward the left. The seizure was controlled by $20 \mathrm{mg}$ diazepam, midazolam $(5 \mathrm{mg}$, $3 \mathrm{mg} / \mathrm{h})$, valproate acid $(80 \mathrm{mg} / \mathrm{h})$, cortisol $(40 \mathrm{mg})$ and mannitol and levetiracetam (1000 mg, oral). The blood pressure was $189 / 104 \mathrm{mmHg}$, and the oxygen saturation dropped to $87 \%$. She was then occupied with invasive ventilator and sent to intensive care unit (ICU) for further life support. The cerebrospinal fluid showed no evidence of infection or autoimmune pathology. She was then diagnosed as PRES. Urapidil $(100 \mathrm{mg} / 50 \mathrm{~mL}$, $3 \mathrm{~mL} / \mathrm{h})$ and prazosin $(4 \mathrm{mg} /$ day $)$ were administered to control the blood pressure.
In the ICU care, she received anti-infection, sedative, blood pressure treatment and blood transfusion. The withdrawal of midazolam and valproate acid resulted in daily convulsion in face and upper limbs for $30 \mathrm{~s}$. After seizure was temporally controlled on day 59 , she was transferred back to department of hematology for further treatment.

The patient reported blurred vision and decline of left side muscle strength from day 73 , and no abnormality was found in the ophthalmic screening. On day 95, she developed acousma and was treated with olanzapine ( $5 \mathrm{mg} /$ day) and sertraline $(25 \mathrm{mg} /$ day). On day 101 , the general condition was improved, and the invasive ventilator was weaned. She was discharged on day 103. At discharge, she complained auditory hallucinations, focal onset seizure and impaired vison. The treatment with levetiracetam, olanzapine, sertraline, prazosin and mycophenolate was continued. The course of her blood pressure fluctuation is shown in Fig. 4.

One month after the discharge, she experienced prolonged generalized tonic clonic seizures at night for $>10 \mathrm{~min}$ and was treated with levetiracetam, valproate acid and pregabalin. The follow-up MRI showed similar impairment as the acute phase (Fig. 3).

\section{Discussion}

Since the first description of PRES in 1996, discussions have been widely carried out on the clinical features and pathology of this disease [7]. The exact mechanism of this syndrome is not yet fully understood. While varied etiologies have been reported, there are two main hypotheses regarding the pathophysiology of PRES. The vasogenic 




Fig. 3 a MRI of case 2 on day 38. The parietal lobe, the frontal lobe and the occipital lobe exhibited index finger-like abnormality, short T1, long T2, high FLAIR signal. b. MRI of case 2 on day 102. The signals showed significant attenuation

hypothesis proposes that the elevation of blood pressure leads to the failure of cerebral autoregulation, and finally causes damage of blood-brain barrier and the secondary vasogenic edema [8]. This hypothesis efficiently explains the relief of symptoms and cerebral edema after normalization of the blood pressure. However, about 20 to $30 \%$ of PRES patients present with nearly normal blood pressure, thus arguing against this hypothesis [9]. The other theory considers the blood pressure elevation as the consequence of primary endothelial dysfunction [10], as patients exposed to treatment regimens with immunosuppressive agents or cytotoxic medication would experience endothelium injury which causes vascular leakage and edema formation [11]. Recently, autoimmune disorders have been reported to contribute to PRES through the endothelial injury by antigen-antibody interaction and endothelial inflammation. Recent cerebral perfusion imaging studies have revealed conflicting perfusion patterns among PRES patients with various etiologies, which may be a result of primary hypertension and cerebral hyperperfusion versus endothelial dysfunction, cerebral vasoconstriction and subsequent cerebral hypoperfusion. The different mechanisms could be overlapping or even interact with each other. Treatment of the cause-related factor like hypertension would be critical to favorable outcomes.
On the other hand, PRES patients with different pathophysiological etiologies share common imaging and clinical manifestations. The diagnosis of PRES is often made after excluding other diagnoses. The treatment of PRES is also non-specific, but the elimination of precipitating causes is the main goal [1]. Cohort studies have also found that the control of causative factor, toxemia of pregnancy, and hyperglycemia are the independent factors in 90-day outcome. Traditionally considered as a "reversible" syndrome, 44\% survivors of severe PRES resided functional impairment [6]. The development of nonconvulsive seizure and related epileptiform patterns is associated with a worse outcome, therefore prompt treatment with anti-epileptic drugs is of major importance. The effect of hypertension control on the outcome of PRES is among the consensus of clinicians despite the limited evidence. The second case presented here had withdrawal of ciclosporin instantly after the psycho-neurological presentations, then she developed seizure and status epilepticus 6 days later. In patients with or without vasogenic initial factor, the rise of blood pressure would possibly activate the secondary impairment which might lead to unfavorable outcome or even mortality. But above all, the clinicians should keep in 


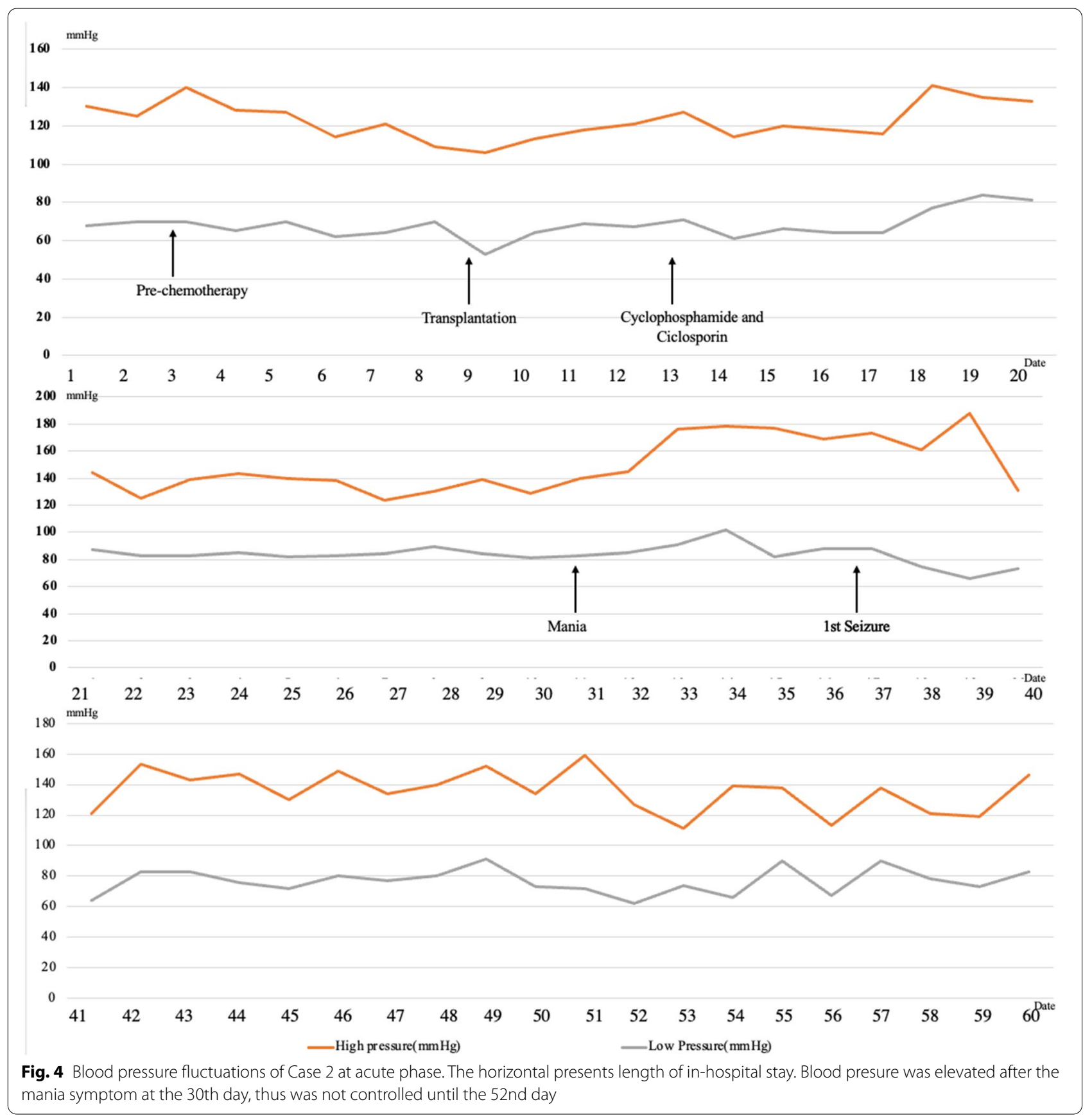

mind the possibility of PRES and start treatment of hypertension as early as possible.

\section{Conclusions}

According to current evidence, the precise pathophysiology behind PRES was yet understood. The two cases presented, and the previous literature showed the primary and secondary prolonged blood pressure fluctuations would be a potential predict factor in the prognosis of this syndrome. Early and efficient blood pressure management should be applied in PRES patients for a more favorable outcome.

\section{Abbreviations}

PRES: Posterior reversible encephalopathy syndrome; RPLS: reversible posterior leukoencephalopathy syndrome; PAP: pulmonary artery pressure; TA-TMA: transplantation-associated thrombotic microangiopathy. 


\section{Acknowledgements}

We sincerely thank the patients and the family for the detailed information and the help to this work.

\section{Authors' contributions}

DZ developed the original idea, DZ, WX, and LL participate in the clinical diagnosis and treatment of the patients. $L \mathrm{~L}$ collected the case information and draft the main body of the paper. YZ and YX reviewed and edited the manuscript. The author(s) read and approved the final manuscript.

\section{Funding}

This work was supported by grants from the National Natural Science Foundation of China $(81801294,81871017,81420108014)$, the Post-Doctoral Research Project of West China Hospital at Sichuan University (2018HXBH023), and the 1.3.5 Project for Disciplines of Excellence of West China Hospital at Sichuan University (ZY2017305, ZYGD20011).

\section{Availability of data and materials}

The datasets used and/or analyzed during the current study are available from the corresponding author on reasonable request.

\section{Declarations}

\section{Ethical approval and consent to participate}

The Ethics Committee of West China Hospital, Sichuan University (2019[210]) approved this study.

Written informed consent was obtained from the patient and her guardians.

\section{Consent for publication}

All the authors are consent for the publication of this article.

\section{Competing interests}

Author Dong Zhou is the associate editor for Acta Epileptologica. Author Dong Zhou was not involved in the journal's review of, or decisions related to this manuscript.

Received: 1 December 2020 Accepted: 9 November 2021

Published online: 13 December 2021

\section{References}

1. Fugate JE, Rabinstein AA. Posterior reversible encephalopathy syndrome: clinical and radiological manifestations, pathophysiology, and outstanding questions. Lancet Neurol. 2015;14(9):914-25.

2. Rabinstein AA, Mandrekar J, Merrell R, Kozak OS, Durosaro O, Fugate JE. Blood pressure fluctuations in posterior reversible encephalopathy syndrome. J Stroke Cerebrovasc Dis. 2012;21(4):254-8.

3. Liman TG, Bohner G, Endres M, Siebert E. Discharge status and in-hospital mortality in posterior reversible encephalopathy syndrome. Acta Neurol Scand. 2014;130(1):34-9.

4. Liman TG, Bohner G, Heuschmann PU, Endres M, Siebert E. The clinical and radiological spectrum of posterior reversible encephalopathy syndrome: the retrospective Berlin PRES study. J Neurol. 2012;259(1):155-64.

5. Burnett MM, Hess CP, Roberts JP, Bass NM, Douglas VC, Josephson SA. Presentation of reversible posterior leukoencephalopathy syndrome in patients on calcineurin inhibitors. Clin Neurol Neurosurg. 2010;112(10):886-91.

6. Legriel S, Schraub O, Azoulay E, Hantson P, Magalhaes E, Coquet I, et al. Determinants of recovery from severe posterior reversible encephalopathy syndrome. PLoS One. 2012;7(9):e44534.

7. Bartynski WS. Posterior reversible encephalopathy syndrome, part 2 controversies surrounding pathophysiology of vasogenic edema. AJNR Am J Neuroradiol. 2008;29(6):1043-9.

8. Granata G, Greco A, lannella G, Granata M, Manno A, Savastano E, et al. Posterior reversible encephalopathy syndrome--Insight into pathogenesis, clinical variants and treatment approaches. Autoimmun Rev. 2015:14(9):830-6.
9. Bartynski WS, Boardman JF, Zeigler ZR, Shadduck RK, Lister J. Posterior reversible encephalopathy syndrome in infection, sepsis, and shock. AJNR Am J Neuroradiol. 2006;27(10):2179-90.

10. Fischer M, Schmutzhard E. Posterior reversible encephalopathy syndrome. J Neurol. 2017;264(8):1608-16.

11. McKinney AM, Kieffer SA, Paylor RT, SantaCruz KS, Kendi A, Lucato L. Acute toxic leukoencephalopathy: potential for reversibility clinically and on MRI with diffusion-weighted and FLAIR imaging. AJR Am J Roentgenol. 2009;193(1):192-206
Ready to submit your research? Choose BMC and benefit from:

- fast, convenient online submission

- thorough peer review by experienced researchers in your field

- rapid publication on acceptance

- support for research data, including large and complex data types

- gold Open Access which fosters wider collaboration and increased citations

- maximum visibility for your research: over $100 \mathrm{M}$ website views per year

At BMC, research is always in progress.

Learn more biomedcentral.com/submissions 